\title{
sciendo
}

\section{Mapping of the Emergence of Society 5.0: A Bibliometric Analysis}

\author{
Vasja ROBLEK¹, Maja MEŠKO², Iztok PODBREGAR ${ }^{2}$ \\ ${ }^{1}$ Faculty of Organisation Studies, Novo mesto, vasja.roblek@gmx.com \\ ${ }^{2}$ University of Maribor, Faculty of Organizational Sciences, Kranj, Slovenia, maja.mesko@um.si, \\ Iztok.podbregar@um.si
}

\begin{abstract}
Background and purpose: The study aims to answer a research question: With which essential cornerstones technological innovations the transformation from Society 4.0 and Industry 4.0 to Society 5.0 and Industry 5.0 is enabled? The study is important for practitioners and researchers to understand the meaning of Society 5.0 and to familiarise themselves with the drivers that will help shape Society 5.0 policies and play an important role in its further development. Therefore, the authors conducted a quantitative bibliometric study that provides insights into the importance of the topic and incorporates current characteristics and future research trends.

Methodology: The study used algorithmic co-occurrence of keywords to gain a different insight into the evolution of Society 5.0. Thirty-six selected articles from the Web of Science database were analysed with the bibliometric analysis and overlay visualisation.

Results: The co-occurrence analysis shows that terms artificial intelligence, cyber-physical systems, big data, Industry 4.0, Industry 5.0, open innovation, Society 5.0, super-smart society have been widely used in researches in the last three years.

Conclusion: The study presents a bibliometric analysis to analyse the current and future development drivers of a Society 5.0. According to the results, the transition from Society 4.0 to Society 5.0 can be achieved by implementing knowledge and technologies in the IoT, robotics, and Big Data to transform society into a smart society (Society 5.0). In particular, the conceptwould enable the adaptation of services and industrial activities to individuals' real needs. Furthermore, these technologies allow advanced digital service platforms that will eventually be integrated into all areas of life.
\end{abstract}

Keywords: Society 5.0, Industry 5.0, Information society, Smart society, Data-driven innovations

\section{Introduction}

After 2016 Society 5.0 has become a new research phenomenon, which has been introduced in the Japanese government policies to establish a better, super-smart, and more prosperous human-centred society to help overcome chronic social changes. The strategy represents the Japanese response to other socio-technological strategies as Industry 4.0 in Europe, Industrial Internet in the US and Chinese Made in China 2025 (Harayama, 2017).

According to Harayama (2017), Society 5.0 is directly related to the appearance of the 5th Industrial Revolution (Industry 5.0), and they will both occur when artificial in- telligence (AI) is managed to think and lead the organisational processes independently, which is expected that will emerge in 2030.

It is expected that Society 5.0 will continue with the evolution of human and technology relations through a cyber-physical system (CPS; Shiroishi, Uchiyama, \& Suzuki, 2018) which began in the current Industry 4.0. In the last few years, therefore, investment has accelerated in research \& development $(\mathrm{R} \& \mathrm{D})$ of cognitive computing based on AI, and it is expected that it would shortly enable complete self-managed organisation (Roblek, Erenda, \& Meško, 2020) and humans to machine communication and cooperation (Guzman \& Lewis, 2020). Thus, the relations between people and technology can improve the quality of

Received: 12th April 2021; revised: 11th September 2021; accepted: 25th October 2021 
life and ensure sustainable development in all areas (education, health, democracy, economy) (Ferreira \& Serpa, 2018). However, on the other hand, the issue opens to the question of the negative impact of AI on human society (e.g., errors in algorithms that can cause the death of people because of wrong decisions of the computer system, loss of jobs, ethical and economic issues regarding the transfer of responsibility from humans to machines, social control) (Makridakis, 2017).

Based on social changes because of the technology development and known theoretical background about the Society 5.0, the following research question has been set: With which essential cornerstones technological innovations the transformation from Society 4.0 and Industry 4.0 to Society 5.0 and Industry 5.0 is enabled?

The paper includes a scientometric analysis of the co-occurrence keywords and a systematic literature review of existing theoretical explanations of Society 5.0, research on and its development mechanisms that can impact the further transition from Industry and Society 4.0 to Industry and Society 5.0.

\section{Theoretical background}

\subsection{Historical evolution of information society}

The emergence of the third industrial revolution (which began around 1960) was based on the invention of the transistor and the microprocessor. These innovations enabled the accelerated development of telecommunications and computer technology. Automation of processes began, followed by the penetration of computing with computers such as the IBM 370. Thus, society began to move from producing goods and making profits to a post-industrial society based on knowledge production and the growth of service activities (Hughes, 2004). In the 1980s, a shift occurred with digitalisation, which contributed to the post-industrial or information society, which focuses on the organisation of knowledge and serves as social control, guiding innovation and change (Peters, 2020). Table 1 shows the crucial technological factors for a successful transformation process, and Table 2 shows the key economic factors. The emergence of the Internet led to an exposure of a global information society that aims to provide access to the Internet, better education, business support, and networking. All this leads to Castells' opinion that post-industrial society needs to be replaced by information society (Castells, 1996). Since the existing information societies are based on a capitalist system, it is also necessary to emphasise information systems institutional and cultural diversity (e.g. the differences between individual nations and countries) (Salehan, Kim, \& Lee, 2018). The modern information society is based on inno- vative technological solutions for knowledge creation and data processing. The information society has focused on collecting and processing data at several stages (Abubakar et al., 2019).

We can conclude that we understand society as a special form of social organisation in which information, its collection, processing and transmission become the primary source of power and productivity.

\subsection{Industry 4.0 and emergence of Society 5.0}

Industry 4.0 represents a completely new way of integrating technology into society. New technologies are being researched and developed that connect the physical, digital and biological worlds, which affect all disciplines, economies and industries (Caruso, 2018). Industry 4.0 appears as a continuation of the third industrial revolution. It enables the digital interconnection of products, machines, tools and more. It brings 3D printers, self-driving vehicles, AI, and nanotechnology, but unlike the second and third industrial revolutions based on raw materials and energy, Industry 4.0 emphasises knowledge as an essential resource (Roblek et al., 2016).

One of the most important innovations in Industry 4.0 is robotics. Robots have been around for several decades, but the question arises as to why today's robots are different from those of the past? The difference is that robots and humans are now equal partners, meaning robots today have a higher level of artificial intelligence. Furthermore, they can communicate with machines and humans through smart devices. Therefore, it is important to compare and list the special human abilities concerning robots' unique abilities. It becomes clear where robots can help us and what human characteristics they can replace with their unique abilities. With the emergence of robots in everyday human life, the question of taxing not only internet companies but also robots increased, as some scholars suggest that "whoever owns the robots rules the world" (Freeman, 2015). Holder et al. (2016) discuss the identification of the main legal and regulatory implications of robotics. According to the authors, it is time to start a dialogue in society about "how our existing legal framework may need to be adapted and changed to meet the demands of the robotics era."

The negative connotations of Industry 4.0 are seen in reducing the number of employees, and the entire industrial revolution is accompanied by the abolition and creation of new jobs. There are also three crucial areas of concern: inequality, cybersecurity and identity (Schwab \& Davis, 2018). In addition to creating inequalities between people, it can also lead to an even more significant gap between the countries' economies. Less developed economies that are just beginning to industrialise would lag even further behind developed ones (Hughes \& Southern, 2019). When it 
Table 1: Technology-based society and transformation processes-technological factors

\begin{tabular}{|c|l|c|}
\hline \multicolumn{1}{|c|}{ Factor } & \multicolumn{1}{|c|}{ Main topics } & \multicolumn{1}{c|}{ Author } \\
\hline Computerisation (1960-) & $\begin{array}{l}\text { The invention of the transistor and the microprocessor had } \\
\text { an important impact on the rise of telecommunications } \\
\text { and computer technology. }\end{array}$ & $\begin{array}{c}\text { Ensmenger, 2012; } \\
\text { Frey \& Osborne, 2017; } \\
\text { Jorgenson, } 2001\end{array}$ \\
\hline \multirow{5}{*}{ Digitalisation (1980-) } & $\begin{array}{l}\text { Word digitalisation cannot be used as a synonym for com- } \\
\text { puterisation. In business administration, digitalisation } \\
\text { often means the adoption and increased use of informa- } \\
\text { tion and communications technologies. Other meanings } \\
\text { of the word digitalisation are connected with the process } \\
\text { of converting something to digital form (e.g., digitalisation } \\
\text { of payments, digitalisation of the printed documents and } \\
\text { books, the transformation of the analogue signals in a dig- }\end{array}$ & $\begin{array}{c}\text { Katsikas \& Gritzalis, } \\
2017, \text { Valenduc \& } \\
\text { Vendramin, 2017 } \\
\text { ital representation) }\end{array}$ \\
\hline Informatisation (2011-) & $\begin{array}{l}\text { The word informatisation is used to introduce and adopt } \\
\text { information systems, technologies, for instance, informa- } \\
\text { tisation of the company (self-management organisation, } \\
\text { public apparatus, business). }\end{array}$ & $\begin{array}{l}\text { Paulin, 2019; Schuetz } \\
\text { \& Venkatesh, 2020; } \\
\text { Sony and Naik, 2020 }\end{array}$ \\
\hline
\end{tabular}

Table 2: Technology-based society and transformation processes-economic factors

\begin{tabular}{|c|c|c|}
\hline New economy (1980-2006) & $\begin{array}{l}\text { Within the information society, the so-called new econo- } \\
\text { my has been established. During this period, the contri- } \\
\text { bution of information companies and service activities } \\
\text { (e.g., trade, publishing, entertainment, consulting) in the } \\
\text { developed countries expanded to such an extent that it } \\
\text { exceeded production agriculture measured by the contri- } \\
\text { bution to the gross national product. Thus, in general, an- } \\
\text { alysts use the term information economy or new economy } \\
\text { to describe a situation where the gross national product } \\
\text { dominates the information industry. }\end{array}$ & $\begin{array}{l}\text { Cant, 2020; Daveri, } \\
\text { 2002; Farell, } 2003\end{array}$ \\
\hline $\begin{array}{l}\text { Innovative economy or } \\
\text { knowledge-based economy } \\
(2003-2030)\end{array}$ & $\begin{array}{l}\text { The new economy is passed into an innovative econo- } \\
\text { my based on the thesis that capital accumulation is the } \\
\text { main vehicle for economic growth. The rate of economic } \\
\text { growth in the innovative economy depends on the prod- } \\
\text { ucts and services resulting from knowledge (R\&D) }\end{array}$ & $\begin{array}{l}\text { Chen (2008); Drucker } \\
\text { (2002); Tocan (2012) }\end{array}$ \\
\hline Data Economy (2011-) & $\begin{array}{l}\text { Industry } 4.0 \text { enable that humanity is generating more } \\
\text { information than an individual can implement. It is also } \\
\text { coming to the situation that more interdependencies } \\
\text { emerging than an individual can handle, and rapid chang- } \\
\text { es have been observed that are difficult to track. ICT and } \\
\text { big data analytics have given rise to the "data economy". } \\
\text { Society is coming to data accumulation instead of capital. } \\
\text { Data's key features become: data present a by-product } \\
\text { of economic activity; data is the information used for } \\
\text { prediction and uncertainty reduction enhances organi- } \\
\text { sations profit. Implementing data-driven solutions in the } \\
\text { human ecosystem enables the flow of services, opera- } \\
\text { tions and functions and the design and implementation of } \\
\text { strategies and policies. The government policies allow the } \\
\text { emergence of open data (freely available) }\end{array}$ & $\begin{array}{l}\text { Farboodi \& Veldkamo, } \\
\text { 2021; Teece, 2018: } \\
\text { Wamba et al., } 2019\end{array}$ \\
\hline
\end{tabular}


is going for the security in Industry 4.0, the digital world's combination with new technologies creates new battlefields, especially in the cyber world, increases access to lethal technologies, and makes administration and negotiations between countries to secure peace more difficult (Horowitz, 2019). The Industry 4.0 technologies also offer expanded possibilities for warfare, which are increasingly available to state and non-state actors, such as autonomous weapons, nanomaterials, biological and biochemical weapons, portable devices and distributed energy sources (Yoo, 2017). New AI-based autonomous weapons also pose a potential threat to humanity. Without legal restrictions on these technologies' operation and development, there may be unauthorised use for terrorist purposes and likely AI dominance over humans in the fifth industrial revolution (Russel et al., 2015). In addition to concerns about growing inequality and security threats, this fourth industrial revolution also affects us as individuals and community members, i.e., our identity. Digital media are already becoming the main driver of our individual and collective shaping of society and community. They connect people to individuals and groups in new ways, fostering friendships and creating new interest groups. Moreover, such connections transcend many traditional boundaries of interaction (Davis, 2016).

Industry 4.0 has led to a digital transformation of the information society (in business and private life) and the future of Society 5.0. The future society members who will benefit from living and working in smart urban areas will enjoy their advantages enhanced by technological, social and cultural aspects that enable the concept of smart living. The Japanese government introduced Society 5.0 in 2016 as the 5th Science and Technology Master Plan (Cabinet Office, 2016). The concept was described as a vision of a

Table 3: Journals used for the scientometric analysis and systemic literature review

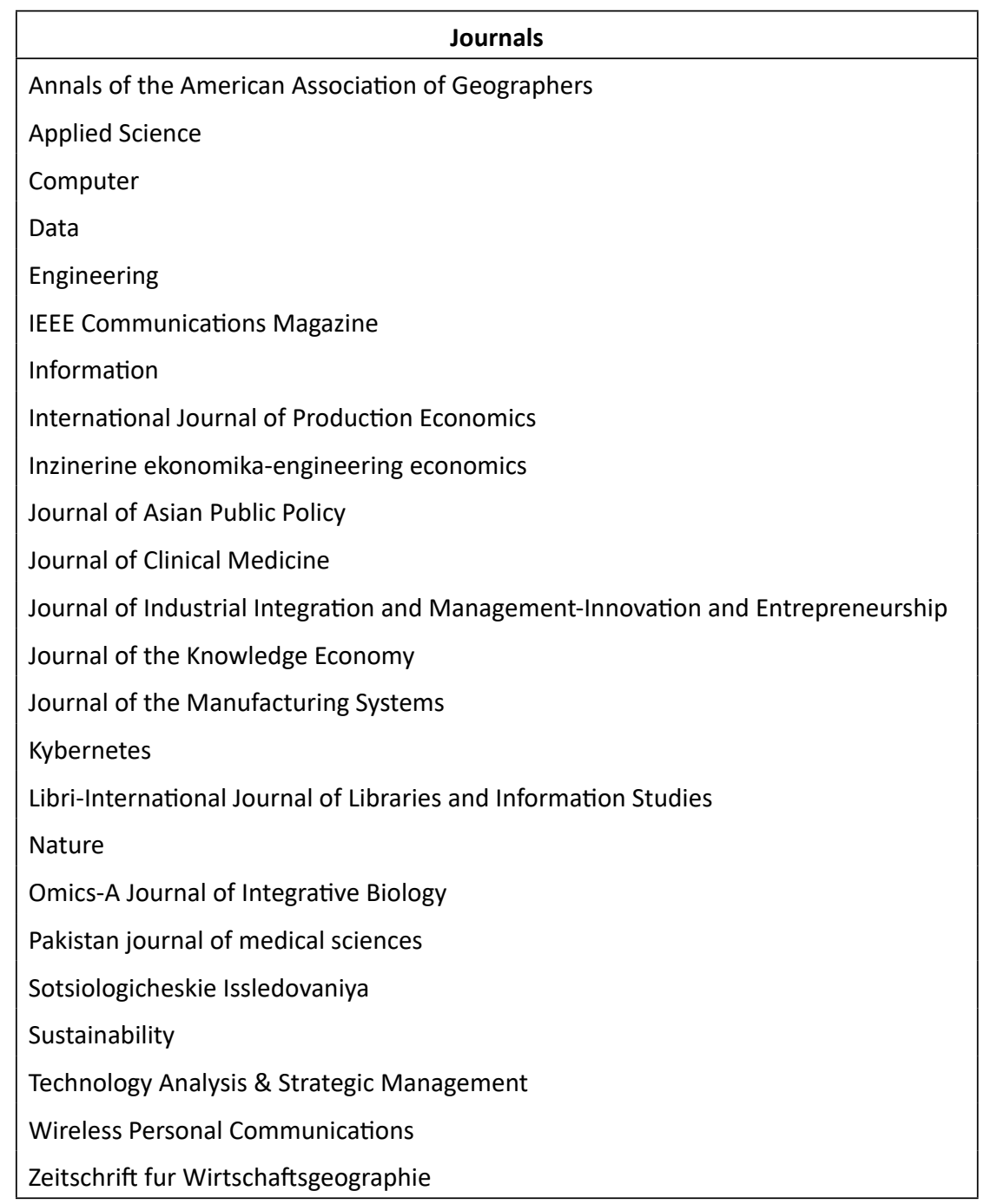


future society characterised by scientific and technological innovation. It aims to create a society centred on human beings that, by merging the physical world with cyberspace, will facilitate economic development and ensure a high quality of life for all citizens (Fukuda, 2020; Potočan, Mulej and Nedeljko, 2020).

\section{Research methodology}

The study aims to provide an interpretive overview of the emergence of Society 5.0, and it is prepared using a mixed research methodology. The study was designed
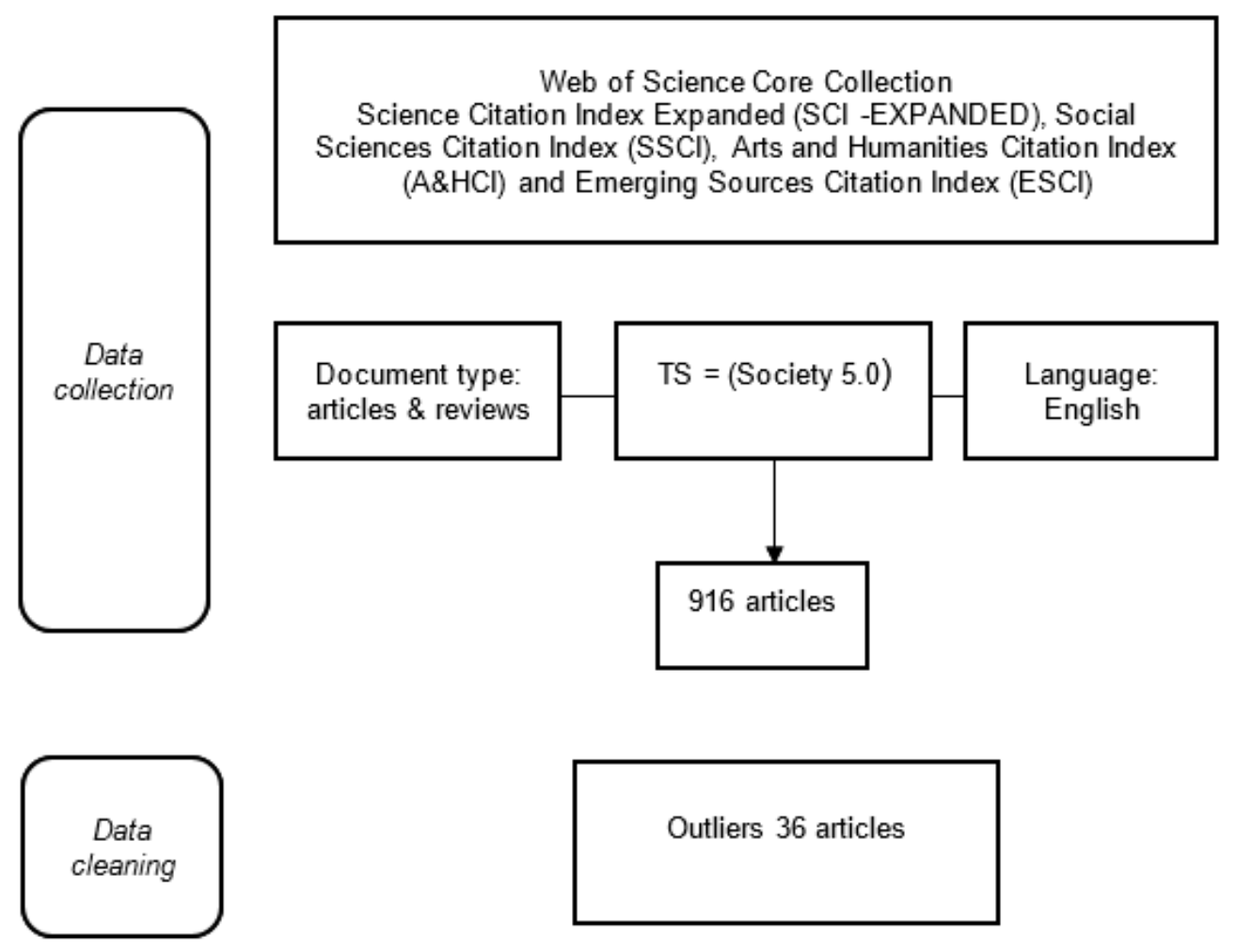

Outliers 36 articles
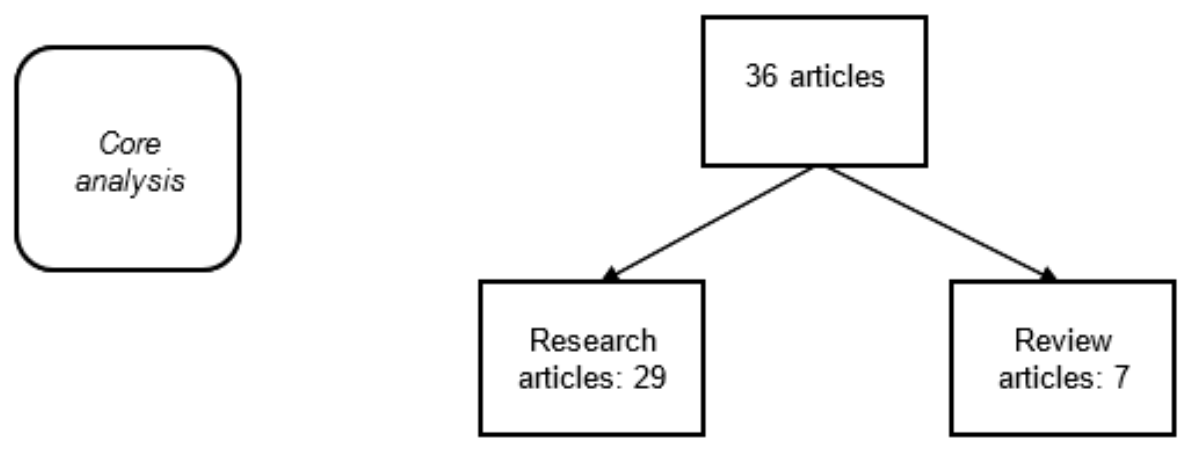

Figure 1: The three steps study protocol 
with the software Vosviewer version 1.6.16 and includes scientometric research used to construct density visualisation and identify the topic clusters based on the keywords co-occurrence (van Eck \& Waltman, 2020). In selecting the literature, was followed the three-step protocol approach used in previous studies such as Chandra and Walker (2020), Dabić et al. (2020), and Palumbo et al. (2021). A three-step protocol (Figure 1) includes i) data collection: selecting articles published in scientific journals indexed in the Web of Science database; ii) data cleaning: a manual review of article titles and abstracts. Based on their content, we excluded articles that were inappropriate in terms of content; and 3) basic analysis: in-depth review of the articles covered. The search itself is divided into two parts. The first part includes the articles' classification according to scientometric research, and the second part is followed by an interpretation of the articles' content. Table 3 presents papers from the journals used in analyses.

The first phase includes the data collection process. The search for articles was done in the Web of Science and Scopus databases. The Boolean keyword combination was used to search for the relevant papers $(\mathrm{TS}=$ (Society 5.0) AND LANGUAGE: (English) AND DOCUMENT TYPES: (Article, Review) Indexes = SCI-EXPANDED, SSCI, A\&HCI and ESCI). It was no temporal restrictions. The search results were limited to the research and review articles published in the refereed journals only. The peer review was limited to scientific journals written in English and was not intended to provide a comprehensive assessment of the state's totality. In the second phase (data cleaning), only the important papers whose content fits the research area were included along with their topics. The papers' content (titles, abstracts, keywords and conclusion) was manually reviewed, and those whose content did not match the research phenomenon were eliminated. In the third phase (core analyses), the information from 36 papers was exported from the WOS, all selected papers' data were chosen and then exported in text format. The data were then imported into Vosviewer version 1.6.16. The search was performed on April 142021.

The WOS database was used as a literature source because it is the most reliable and comprehensive source of data and is frequently used in bibliometric research on the progress and evaluation of various scientific fields (Bernatović et al. 2021).

\section{Results and discussion}

\subsection{The visualisation of the topic clusters}

Figure 2 is a visual representation of the cluster analysis results based on the co-occurrence of keywords. In table 4 are presented the clusters with their most important keywords. First, in the analysing process, a minimum number of occurrences of keyword one was determined. Of the 136 keywords, 102 keywords meet the threshold. Next, the authors manually removed seven keywords related to the choice of research methods in the articles and are not associated with the topic's content (e.g., content analysis, methodology, case study). Then, for the remaining 95 keywords, the overall strength of the co-correlation links with other keywords was calculated.

A total of nine clusters were found. Some of the clusters were interwoven with each other. However, as shown in Figure 2, the clusters are mostly relatively far apart from each other. Therefore, it can be concluded that most of the topics covered in this literature review do not overlap.

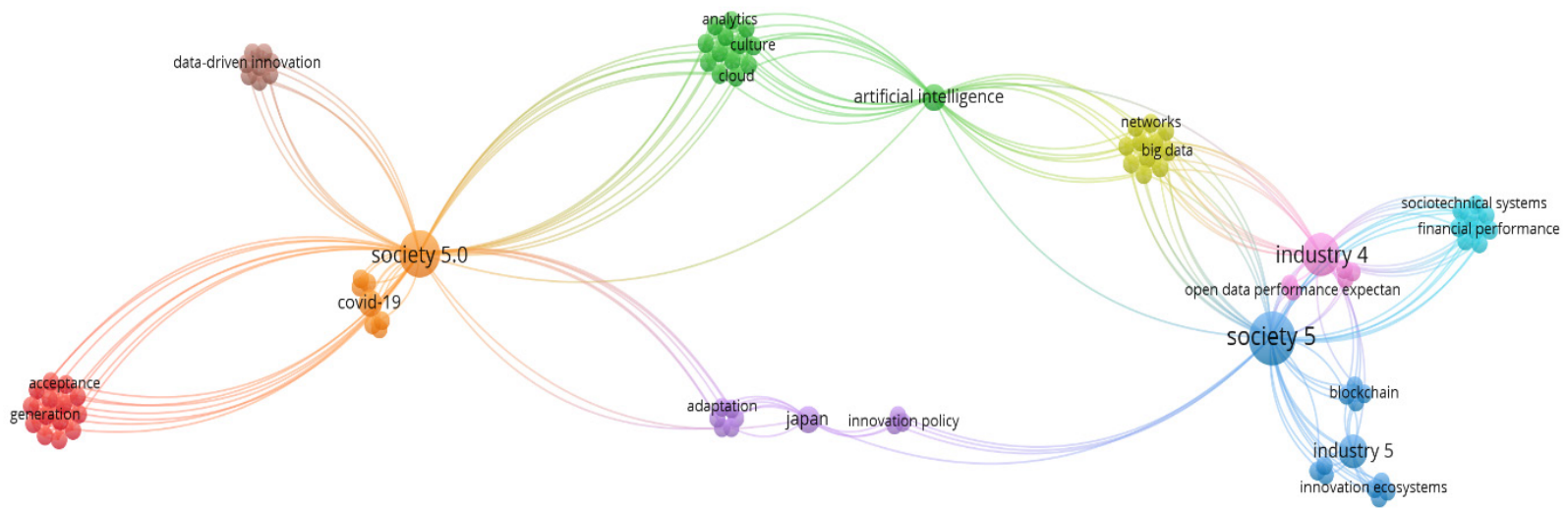

Figure 2: Co-occurrences of keyword network (min. 1). Data source: WOS. Visualisation: VOSviewer 
Each cluster offers a different topic. Thus, all nine clusters provide a comprehensive overview of what is already known about Society 5.0. We did not need to reduce the number of clusters because we wanted to discover the broadest knowledge from homogeneous pieces to present a new social phenomenon. This approach allowed us to give a comprehensive view of research and theory in the field of Society 5.0.

On average, the clusters contained nine articles, ranging from a minimum of 4 to a maximum of 12 . According to the topics, the clusters can be divided into a part related to the consideration of Society 5.0 itself and a second part associated with Industry 5.0. The naming of clusters is based on the authors' personal views and experiences of the research topic. According to the co-occurrence analysis, up to the present day, it can be concluded that terms artificial intelligence, cyber-physical systems, big data, Industry 4.0, Industry 5.0, open innovation, Society 5.0, super-smart society have been widely used in researches in the last three years.

\subsection{Systematic literature review}

As part of the systematic analysis of the articles, according to the content of each cluster, authors have decided to group clusters 2- Industry 4.0 and transformation processes for Society 5.0, 3- Technological development and 9- Industry 4.0 as well as 5- Society 5.0 and the environment, 7- Society 5.0 and innovations and 8- Society 5.0 and medicine, into subchapters that are rounded off in terms of content due to their semantic similarity.

Table 4: Topic clusters of Society 5.0 research from 2017-March, $312021(n=36)$

\begin{tabular}{|c|c|c|c|c|}
\hline Clusters & Cluster colour in Figure 2 & Topic community cluster & Top items & $\begin{array}{l}\text { Total numbers } \\
\text { of terms }\end{array}$ \\
\hline 1 & red & New approaches in HRM & $\begin{array}{l}\text { generation, work values, } \\
\text { personal innovativeness, } \\
\text { career }\end{array}$ & 14 \\
\hline 2 & green & $\begin{array}{l}\text { Industry } 4.0 \text { and trans- } \\
\text { formation processes for } \\
\text { Society } 5.0\end{array}$ & $\begin{array}{l}\text { Industry } 4.0, \text { cities, culture, } \\
\text { smart society, human-cen- } \\
\text { tred management systems }\end{array}$ & 13 \\
\hline 3 & blue & $\begin{array}{l}\text { Technological develop- } \\
\text { ment }\end{array}$ & $\begin{array}{l}\text { Artificial intelligence, } \\
\text { cyber-physical systems, } \\
\text { big data, open innovation, } \\
\text { Internet }\end{array}$ & 13 \\
\hline 4 & yellow & Industry 5.0 & $\begin{array}{l}\text { Industry 5.0, blockchain, } \\
\text { decentralised web, innova- } \\
\text { tion ecosystems, knowledge } \\
\text { circulation }\end{array}$ & 13 \\
\hline 5 & purple & $\begin{array}{l}\text { Society } 5.0 \text { and the envi- } \\
\text { ronment }\end{array}$ & $\begin{array}{l}\text { Super-smart society, innova- } \\
\text { tion policy, climate change, } \\
\text { disaster management, Japan }\end{array}$ & 10 \\
\hline 6 & light blue & $\begin{array}{l}\text { Corporate social respon- } \\
\text { sibility }\end{array}$ & $\begin{array}{l}\text { CSR, financial performance, } \\
\text { ISO } 26000 \text {, organisational } \\
\text { innovations, sociotechnical } \\
\text { systems, social responsible } \\
\text { economic }\end{array}$ & 9 \\
\hline 7 & orange & $\begin{array}{l}\text { Society } 5.0 \text { and innova- } \\
\text { tions }\end{array}$ & $\begin{array}{l}\text { data-driven innovation, } \\
\text { technology and innovation, } \\
\text { system resilience, productiv- } \\
\text { ity and growth, science }\end{array}$ & 9 \\
\hline 8 & brown & Society 5.0 and medicine & $\begin{array}{l}\text { Covid- } 19, \mathrm{Al} \text {, emerging tech- } \\
\text { nology, medicine } 4.0 \text {, the } \\
\text { industrial revolution }\end{array}$ & 8 \\
\hline 9 & light purple & Industry 4.0 & $\begin{array}{l}\text { Industry } 4.0 \text {, digitalised soci- } \\
\text { ety, open data performance, } \\
\text { SDGs, super-smart society }\end{array}$ & 6 \\
\hline
\end{tabular}




\subsubsection{Society 5.0 and social changes}

In the modern world, the process of digitalisation is strongly embedded in social processes. It thus influences changes in the contexts of reference for human action and increasingly shapes human-machine relations. The importance of the technological approach for the future transformation of societal processes is already evident in the Japanese concept of Society 5.0, which has emerged as a strategic national policy initiative. The concept goal is to transform the science, technology and innovation system toward Society 5.0 (Fukuda, 2020). The actual purpose of this strategy is defined by Hayashi et al. $(2017,264)$ as follows:

$\gg \ldots$ create new values by collaborating and cooperating with several different systems, and plans standardisation of data formats, models, system architecture, etc. and development of necessary human resources. Besides, it is expected that enhancements of intellectual properties development, international standardisation, IoT system construction technologies, big data analysis technologies, artificial intelligence technologies, and it is encouraging Japans competitiveness in a»super-smart society. "

According to the authors, it is a serious concept of social development that will affect all levels of society. The concept elements are based on the role of individual technology relationship by promoting the quality of life in a sustainable world and the emergence of a superintelligent society. Yousfikhahb (2017) has highlighted that if society 5.0 is to be a successful concept, it must integrate innovation policies (from the government), entrepreneurship (from the society) and entrepreneurial skills (from the civil society and institutions). The author also warns that "the social aspects of technology are usually underestimated in the policy-making process which may impact limiting the policy intentions underlying the implementation of Society 5.0".

It can be concluded that self-organisation in smart technologies has an important influence on the future societal impact of smart technologies. Human self-organisation will depend on the availability of smart technologies in the future, especially in education, business and personal life. The use of smart technologies also opens ethical dilemmas about communication in CPS connexion with personal privacy. These implications can be found in a more dynamic social system in terms of socialisation, but it can also lead to negative consequences, such as losing personal contact with friends and family (Roblek, Meško, Dimovski, and Peterlin, 2019; Shiroishi et al., 2018).

\subsubsection{Society 4.0 and transformation to Society $\mathbf{5 . 0}$}

Society 4.0 was created based on a German economic program called Industry 4.0. To this program, Germany aimed to boost the economy in Germany and all of Europe. The Japanese responded with the concept of Society 5.0. If European countries rely on the gradual integration of artificial intelligence and other cutting-edge technologies to further develop an innovatively designed economy, the Japanese have decided to go beyond this concept and take the next step in data-driven social development to establish Society 5.0 (Onday, 2019).

The main goal of Society 5.0 is to enable the wellbeing of citizens provided by available system services that also enable value creation for society (e.g., economic development, social transformation, and economic growth). Therefore, the program implementation introduced next-generation technologies, governance reform, and value-creating strategies developed for urban centres (Fukuda, 2020).

The aim of Society 5.0 is to further combine innovative knowledge with the use of AI, which is only in the concept or development phase, and to offer new human-centred technological solutions in all areas of human activity. It should be noted that Society 4.0 focuses more on technological solutions in the field of digitalisation of businesses and local government processes, intending to improve the efficiency and effectiveness of the operational and financial processes of private and public organisations and public administration (Pereira, Lima, \& Charrua-Santos, 2020). On the other side, Society 5.0 is expected to be more involved in all population groups' general social development. Thus, there would be a commercial focus on using new technologies and what is called social robotics. Therefore, AI, IoT, virtual reality, algorithms, cyber-physical systems (CPS) would lead to positive social effects that can be incorporated under this technology (Serpanos, 2018; Song, Song, Timakum, Ryu, \& Lee, 2018):

- Home automation for independent living (home security and safety systems, motion sensors, remote monitoring, indoor air quality control, smart lighting, safe bed, smart sofa, domestic/service robots),

- health and wellbeing for functional ability (safety bracelets, activity wristbands, personal health monitor, smart medicine disappearances, exercise and memory games, smart rollator, daily medical testing) and active participation and social inclusion (entertainment and news, smart governance, online work, video chat, remote medical consultation).

CPS presents the urban governance system and enables the emergence of the so-called smart community that thrives in the data economy (Kuru \& Ansell, 2020). Communities also began with the research about the modes of preparation for transforming the local community into a smart community, including fintech solutions. The city's urbanisation has to enable urban solutions to become suitable for implementing and integrating the information technologies (Alawadhi et al., 2012). The Canadian Governance Center at The Ottawa University was criticised for its research approach, which they felt was too technically oriented. They suggested that research concepts should be 
more governance-oriented, emphasising the importance of social relations and social capital in urban development (Albino, Berardi, \& Dangelico, 2015). The lack of generally accepted definitions that would clearly explain these terms is partly due to the different scientific fields from which they originate and partly due to changing trends.

\subsubsection{Emergence of the Industry 5.0}

If Industry 4.0 has been introduced, the concepts such as CPS, IoT, blockchain, smart factory, big data, cloud storage and cybersecurity, which all have an important function for manufacturing efficiency and lower costs of production (Nahavandi, 2019; Jerman et al., 2020), Industry 5.0 is going beyond Industry 4.0. The focus of Industry 5.0 is on the interaction between machines and semi-finished products, individual machine parts, robots and people. For this process to succeed, the use of big data is essential. Therefore, it is going for a technology that enables the collection and processing of large amounts of data in real-time (Büchi, Cugno, \& Castagnoli, 2020). Furthermore, for the transition to Industry 5.0 itself, it is important to make rapid progress in the areas of AI, machine learning (ML), robotics, Internet of Things (IoT), autonomous vehicles and cars, 3D and 4D printing, virtual and augmented reality, wearable materials, additive manufacturing, nanotechnology, biotechnology, energy storage and quantum computing (European Commission, 2021).

According to the European Commission, in January 2021, it adopted the document Industry 5.0: Towards a more sustainable, resilient and human-centric industry. It follows that Industry 5.0 complements and expands Industry 4.0. Thus, Industry 5.0 focuses on aspects that will shape economic and technological development and determine the direction of industrial policies in the future European society. These factors also have environmental, social and fundamental rights dimensions. The document emphasises that Industry 5.0 should not be compared as a chronological continuation of the Industry 4.0 paradigm, nor should it be understood as an alternative. The document is thus defined as (European Commission, 2021).

"The result of a forward-looking exercise to help frame how European industry and emerging societal trends and needs can co-exist".

\subsubsection{Corporate social responsibilities}

According to Keidanren (2016, 3), Society 5.0 presents a new vision of society:

»that incorporates several new technologies in all industries and social activities and achieves both economic development-primarily based on Sustainable Development Goals established by the United Nations, and solutions to key social problems in the present society«.
As part of the implementation of the concept of Society 5.0 in Japan, Keidanren (Japan Business Federation) amended the Charter of Corporate Behavior, also added the section on "Achieving a Sustainable Society" as part of the amendments, with the primary goal of proactively achieving the Sustainable Development Goals. SDGs) by creating a Society 5.0 (Fukuyama, 2018). According to these changes, Society 5.0 enabled a responsible human-centred society and offered a promising integral framework for the potential development of CSR in organisations (Potočan et al., 2020).

\subsubsection{Society 5.0 and social innovations}

Within the societal innovations associated with Society 5.0, we focus on the impact of innovative technologies in healthcare, climate change, and disaster management. It is expected that new technologies in the medical field will also become one of the capillaries of Society 5.0. Thus, smart tools adapted to medical needs include material innovations, nano-devices, and smart technology (sensors, controls) (Lewis, Gandomkar, \& Brennar, 2019), making their way into medicine. Artificial intelligence is also playing an increasingly important role in medicine. For example, AI-based medical image analysis has already been established in some Covid ten centres. In addition, AI is becoming increasingly customer-centric and impacting the quality of medical services (Vaishya et al., 2020).

In climate change and disaster management, a transformation of disaster and climate change management is expected in the context of innovative solutions brought by Society 5.0. Environmental and climate change requires the development of technologies that enable the early detection and adaptation of hazards. The goal is to provide faster and more effective information. Increased use of technology in Society 5.0 is also expected to improve environmental and public health protection (Mavrodieva \& Show, 2020).

\section{Discussion and conclusion}

According to the co-occurrence analyse of the papers key words were the most discussed topics careers, Society 5.0 in connection with Covid-19, data-driven innovation, cities, analytics, enterprise systems, big data, knowledge, Society 5.0 in relationship with digitised society, open data, performance expectations, Industry 5.0, blockchain, critical juncture.

The paper discusses a series of activities necessary to transfer modern knowledge and new technologies, typical of the fourth industrial revolution or Industry 4.0, from research institutes and economic entities to the broader society, Society 5.0. The process can be achieved by implementing knowledge and technologies in the IoT, robotics 
and Big Data to transform the existing society into a smart society (Society 5.0). In particular, the concept would enable the adaptation of services and industrial activities to individuals' real needs, as these technologies allow advanced digital service platforms that will eventually be integrated into all areas of life.

Our study indicates that the more intensive the transition to Society 5.0 will be, the more services and daily tasks can be provided via the cloud, e.g., on the Internet. Therefore, this data processing would send information or enable services related to applications on the telephone, the computer and robots, among others. This will allow individuals to have more free time and the free allocation of other activities because artificial intelligence will replace manual data processing, typical of traditional digital algorithms. Therefore, it will save much time and increase the productivity of the individual. As a result, it will positively affect increasing the value-added in the economy and enhance all generations.

Authors expect that with the emerging Society 5.0, developed economies will solve many social problems through innovation in technology and science. According to some estimates, the share of Japan's working population will shrink from 77 million to about 54 million people by 2050 (National Institute of Population and Social Security Research: IPSS 2017). Economists estimate that it is precisely the demographic problem that will cause fewer and fewer young people to opt for family and children, which means that the number of older people in need of social care will increase. This applies to Japanese society, which faces a similar, equally pressing demographic problem and many European countries (National Institute of Population and Social Security Research: IPSS 2017). In addition, the developed economies face environmental degradation problems, logistical problems (transport of people and goods within cities, between cities and rural areas, and environmental protection or reduction of greenhouse gases - climate change).

The limitations of the research can be divided into content and methodological limitations. Among the content limitations, the presentation of only some aspects of Society 5.0 applies because we used to analyse only the research papers from the WOS database. As methodological limitations, we refer to the boundary associated with the research paradigm. This paper's limitation is that it is based on scientific paper reviews and not on primary research. It is based on a topic whose development for the future capabilities of artificial intelligence depends on a parallel development of cyberspace and its importance for everyday human life. Our study should be taken as inherently biased from an analytical perspective, but at the same time, it enriches us with data that quantitative methods cannot produce.

For future research, we suggest examining and iden- tifying a set of good practices of Society 5.0. in Japan (Pereira et al., 2020) to assess the possibility of their implementation in other countries (especially in developing countries). We also propose future research to consider the risks that may arise in a digital society, e.g., cybersecurity, including possible cyber terrorism, relations between humans and robotics and ethical questions related to AI implementation and enabling of decision-making instead of a human.

\section{Literature}

Albino, V., Berardi, U., \& Dangelico, R. M. (2015). Smart cities: Definitions, dimensions, performance, and initiatives. Journal of Urban Technology, 22(1), 3-21. https://doi.org/10.1080/10630732.2014.942092

Bernatović, I., Slavec Gomezel, A., \& Černe, M. (2021). Mapping the knowledge-hiding field and its future prospects: a bibliometric co-citation, co-word, and coupling analysis. Knowledge Management Research \& Practice, In Press. http://doi.org/10.1080/14778238 .2021 .1945963

Büchi, G., Cugno, M., \& Castagnoli, R. (2020). Smart factory performance and Industry 4.0. Technological Forecasting and Social Change, 150, 119790. https:// doi.org/10.1016/j.techfore.2019.119790

Cabinet Office (2016). 5th Science and Technology Basic Plan by the Council for Science, Technology. Retrieved from http://www8.cao.go.jp/cstp/english/basic/5thbasicplan.pdf

Cant, C. (2020). Riding for Deliveroo: Resistance in the New Economy. Cambridge, UK: Polity Press

Caruso, L. (2018). Digital innovation and the fourth industrial revolution: epochal social changes?. Ai \& Society, 33(3), 379-392. https://doi.org/10.1007/s00146-0170736-1

Castells, M. (1996). The information age. In Thornham, S., Basset, C., \& Marris, P. (Eds.), Media studies, a reader third edition (pp. 152-164). New York, NY: New York University Press.

Chandra, Y., \& Walker, R. M. (2019). How does a seminal article in public administration diffuse and influence the field? Bibliometric methods and the case of Hood's “A Public Management for All Seasons?". International Public Management Journal, 22(5), 712-742. https://doi.org/10.1080/10967494.2018.1498817

Chen, C. K. (2008). Causal modeling of knowledge-based economy. Management Decision, 46(3), 501-514. https://doi.org/10.1108/00251740810863915

Dabić, M., Vlačić, B., Paul, J., Dana, L. P., Sahasranamam, S., \& Glinka, B. (2020). Immigrant entrepreneurship: A review and research agenda. Journal of Business Research, 113, 25-38. https://doi.org/10.1016/j.jbusres.2020.03.013 
Davis, N. (2016). What is the fourth industrial revolution? Retrieved from https://www.weforum.org/agenda/2016/01/what-is-the-fourth-industrial-revolution/

Daveri, F. (2002). The new economy in Europe, 19922001. Oxford Review of Economic Policy, 18(3), 345362. https://doi.org/10.1093/oxrep/18.3.345

Drucker, P. F. (2002). The discipline of innovation. Harvard Business Review, 80(8), 95-102.

Ensmenger, N. (2012). The digital construction of technology: Rethinking the history of computers in society. Technology and Culture, 53(4), 753-776. http://dx.doi. org/10.2307/41682741

European Commission (2021). Industry 5.0: Towards more sustainable, resilient and human-centric industry. Retrieved from https://ec.europa.eu/info/news/industry-50-towards-more-sustainable-resilient-and-human-centric-industry-2021-jan-07_en

Farboodi, M., \& Veldkamp, L. (2021). A Growth Model of the Data Economy. National Bureau of Economic Research. Retrived from https://www.nber.org/papers/ w28427

Farrell, D. (2003). The real new economy. Harvard Business Review, 81(10), 104-12.

Ferreira, C. M., \& Serpa, S. (2018). Society 5.0 and Social Development. Management and Organizational Studies, 5, 26-31. http://doi.org/10.5430/mos.v5n4p26

Frey, C. B., \& Osborne, M. A. (2017). The future of employment: How susceptible are jobs to computerisation?. Technological Forecasting and Social Change, 114, 254-280. https://doi.org/10.1016/j.techfore. 2016.08 .019

Freeman, R.B. (2015). Who owns the robots rules the world. IZA World of Labor, Vol. 5. Retrieved from https://wol.iza.org/uploads/articles/5/pdfs/who-ownsthe-robotsrules-the-world.pdf

Fonseca, D., Conde, M. Á., \& García-Peñalvo, F. J. (2018). Improving the information society skills: Is knowledge accessible for all?. Universal Access in the Information Society, 17(2), 229-245. https://doi.org/10.1007/ s10209-017-0548-6

Fukuda, K. (2020). Science, technology and innovation ecosystem transformation toward society 5.0. International Journal of Production Economics, 220, 107460. https://doi.org/10.1016/j.ijpe.2019.07.033

Fukuyama, M. (2018). Society 5.0: Aiming for a new human-centered society. Japan Spotlight, 27, 47-50.

Guzman, A. L., \& Lewis, S. C. (2020). Artificial intelligence and communication: A Human-Machine Communication research agenda. New Media \& Society, 22(1), 7086. https://doi.org/10.1177/1461444819858691

Harayama, Y. (2017). Society 5.0: Aiming for a new human-centered society. Hitachi Review, 66(6), 556-557.

Hayashi, H., Sasajima, H., Takayanagi, Y., \& Kanamaru, H. (2017). International standardisation for smarter society in the field of measurement, control and au- tomation. Proceedings of the 56th Annual Conference of the Society of Instrument and Control Engineers of Japan (SICE), Kanazava, JA: IEEE, 263-266. https:// doi.org/10.23919/SICE.2017.8105723

Holder, C., Khurana, V., Harrison, F., \& Jacobs, L. (2016). Robotics and law: Key legal and regulatory implications of the robotics age (Part I of II). Computer Law \& Security Review, 32(3), 383-402. https://doi. org/10.1016/j.clsr.2016.03.001

Horowitz, M. C. (2019). When speed kills: Lethal autonomous weapon systems, deterrence and stability. Journal of Strategic Studies, 42(6), 764-788. https://doi.org /10.1080/01402390.2019.1621174

Hughes, T. P. (2004). Human-built world: How to think about technology and culture. Chicago, Illinois: University of Chicago Press.

Hughes, C., \& Southern, A. (2019). The world of work and the crisis of capitalism: Marx and the Fourth Industrial Revolution. Journal of Classical Sociology, 19(1), 5971. https://doi.org/10.1177/1468795X18810577

Jedynak, M., Czakon, W., Kuźniarska, A., \& Mania, K. (2021). Digital transformation of organisations: what do we know and where to go next?. Journal of Organizational Change Management, In Press. https://doi. org/10.1108/JOCM-10-2020-0336

Jerman, A., Bertoncelj, A., Dominici, G., Pejić Bach, M., \& Trnavčević, A. (2020). Conceptual key competency model for smart factories in production processes. Organizacija, 53(1), 68-79. http://doi.org/10.2478/orga2020-0005

Jorgenson, D. W. (2001). Information technology and the US economy. American Economic Review, 91(1), 1-32. https://doi.org/10.1257/aer.91.1.1

Katsikas, S. K., \& Gritzalis, S. (2017). Digitalisation in Greece: State of play, barriers, challenges, solutions. In Paulin, AA, Anthopoulos, GL, \& Reddick, G.C. (Eds.), Beyond Bureaucracy (pp. 355-375). Cham, SU: Springer.

Kuru, K., \& Ansell, D. (2020). TCitySmartF: A comprehensive systematic framework for transforming cities into smart cities. IEEE Access, 8, 18615-18644. https:// doi.org/10.1109/ACCESS.2020.2967777

Lewis, S. J., Gandomkar, Z., \& Brennan, P. C. (2019). Artificial Intelligence in medical imaging practice: looking to the future. Journal of Medical Radiation Sciences, 66(4), 292-295. https://doi.org/10.1002/jmrs.369

Makridakis, S. (2017). The forthcoming Artificial Intelligence (AI) revolution: Its impact on society and firms. Futures, 90, 46-60. https://doi.org/10.1016/j.futures.2017.03.006

Mavrodieva, A. V., \& Shaw, R. (2020). Disaster and Climate Change Issues in Japan's Society 5.0-A Discussion. Sustainability, 12(5), 1893. https://doi. org/10.3390/su12051893

Nahavandi, S. (2019). Industry 5.0-A human-centric 
solution. Sustainability, 11(16), 4371.

https://doi.org/10.3390/su11164371

National Institute of Population and Social Security Research (2017). Population projections for Japan (2017): 2016 to 2065. Retrieved from http://www.ipss.go.jp/ pp-zenkoku/e/zenkoku_e2017/pp29_summary.pdf

Onday, O. (2019). Japan's society 5.0: going beyond industry 4.0. Business and Economics Journal, 10(2), 2-7. https://doi.org/10.4172/2151-6219.1000389

Palumbo, R., Manesh, M. F., Pellegrini, M., Caputo, A., \& Flamini, G. (2021). Organising a sustainable smart urban ecosystem: Perspectives and insights from a bibliometric analysis and literature review. Journal of Cleaner Production, 297, 126622. https://doi. org/10.1016/j.jclepro.2021.126622

Paulin, A. (2019). Smart City Governance. Elsevier, NL: Amsterdam.

Pereira, A. G., Lima, T. M., \& Charrua-Santos, F. (2020). Industry 4.0 and Society 5.0: opportunities and threats. International Journal of Recent Technology and Engineering, 8(5), 3305-3308. https://doi.org/10.35940/ ijrte.D8764.018520

Peters, M.A. (2020). Digital socialism or knowledge capitalism? Educational Philosophy and Theory, 52(2). http://doi.org/10.1080/00131857.2019.1593033

Potočan, V., Mulej, M., \& Nedelko, Z. (2020). Society 5.0: balancing of Industry 4.0, economic advancement and social problems. Kybernetes, 50(3), 794-811. https:// doi.org/10.1108/K-12-2019-0858

Roblek, V., Erenda, I., \& Mesko, M. (2020). Fundamental changes in the organisational processes. In Machado, C. \& Davim, J. P. (Eds.), Industry 4.0: Challenges, Trends, and Solutions in Management and Engineering (pp. 161-190). Boca Raton, FL: CRC Press/Taylor \& Francis Group.

Roblek, V., Mesko, M., Dimovski, V., \& Peterlin, J. (2019). Smart technologies as social innovation and complex social issues of the $\mathrm{Z}$ generation. Kybernetes, 48(1), 91-107. https://doi.org/10.1108/K-09-2017-0356

Roblek, V., Meško, M., \& Krapež, A. (2016). A complex view of industry 4.0. Sage Open, 6(2), 1-12. https:// doi.org/10.1177/2158244016653987

Salehan, M., Kim, D. J., \& Lee, J. N. (2018). Are there any relationships between technology and cultural values? A country-level trend study of the association between information communication technology and cultural values. Information \& Management, 55(6), 725-745. http://doi.org/10.1016/j.im.2018.03.003

Serpanos, D. (2018). The cyber-physical systems revolution. Computer, 51(3), 70-73. https://doi.org/10.1109/ MC.2018.1731058

Schuetz, S., \& Venkatesh, V. (2020). The rise of human machines: How cognitive computing systems challenge assumptions of user-system interaction. Journal of the Association for Information Systems, 21(2), 460-
482. http://doi.org/10.17705/1jais.00608

Schwab, K., \& Davis, N. (2018). Shaping the future of the fourth industrial revolution. New York, NY: Currency.

Shiroishi, Y., Uchiyama, K., \& Suzuki, N. (2018). Society 5.0: For human security and wellbeing. Computer, 51(7),91-95.http://doi.org/10.1109/MC.2018.3011041

Song, I. Y., Song, M., Timakum, T., Ryu, S. R., \& Lee, H. (2018). The landscape of smart aging: Topics, applications, and agenda. Data \& Knowledge Engineering, 115, 68-79. https://doi.org/10.1016/j. datak.2018.02.003

Sony, M., \& Naik, S. (2020). Industry 4.0 integration with sociotechnical systems theory: A systematic review and proposed theoretical model. Technology in Society, 61, 101248. https://doi.org/10.1016/j.techsoc. 2020.101248

Teece, D. J. (2018). Profiting from innovation in the digital economy: Enabling technologies, standards, and licensing models in the wireless world. Research Policy, 47(8), 1367-1387. http://doi.org/10.1016/j.respol.2017.01.015

Tocan, M. C. (2012). Knowledge based economy assessment. Journal of Knowledge Management, Economics and Information Technology, 2(5), 1-13.

Valenduc, G., \& Vendramin, P. (2017). Digitalisation, between disruption and evolution. Transfer: European Review of Labour and Research, 23(2), 121-134. https://doi.org/10.1177/1024258917701379

Van Eck, J.N., \& Waltman, L. (2020). Manual for Vosviewer version 1.6.16. Leiden, NL: University of Leiden.

Vaishya, R., Javaid, M., Khan, I. H., \& Haleem, A. (2020). Artificial Intelligence (AI) applications for COVID-19 pandemic. Diabetes \& Metabolic Syndrome: Clinical Research \& Reviews, 14(4), 337-339.

https://doi.org/10.1016/j.dsx.2020.04.012

Wamba, S. F., Akter, S., Trinchera, L., \& De Bourmont, M. (2019). Turning information quality into firm performance in the big data economy. Management Decision, 57(8), 1756-1783. https://doi.org/10.1108/MD04-2018-0394

Yoo, J. (2017). Embracing the machines: rationalist war and new weapons technologies. California Law Review, 105, 443. http://dx.doi.org/10.15779/Z38D50FX0X

Vasja Roblek, MPhil is a researcher and consultant. He received his B.A. degree in Banking from the University of Ljubljana and MPhil degree in Management from the University of Primorska. He is currently completing his PhD at the Faculty of Organisational Studies in Novo mesto. His main areas of expertise are digital transformation, information society, knowledge management, smart technologies and systemic approaches. He conducts research and consulting for 
various international organisations. His work includes about 110 bibliographic records. He is also associated editor of the World Complexity Science Academy Science Journal. ORCID: 0000-0003-1182-3400

Maja Meško, PhD, is a Full Professor of Management at the Faculty of Management, University of Primorska and full professor of Human Research Management at the Faculty of Organization Science, University of Maribor. She received PhD in kinesiology, the title of her doctoral dissertation is Defining certain motor abilities and psychological characteristics of the Slovenian military pilots. Her research interests include the areas of management, psychology in management, occupational health and management. She has also participated in various projects. She authored or co-authored various scientific papers published in professional and academic journals. ORCID: 00000002-3124-3094.

Iztok Podbregar is a Dean and a Full Professor at the Faculty of Organizational Sciences, University of Maribor. His main research interests concern crisis management, critical infrastructure and human resource management. $\mathrm{He}$ is author of several monographs, scientific articles published in Slovenia and abroad. 